\title{
Causality in the Crime of Willful Murder by Transmission of Coronavirusin the Jordanian Legislation
}

\author{
Saleem Isaaf Alazab \\ ${ }^{1}$ College of Law, Balqa Applied University, Al-Salt City, Jordan \\ Correspondence: Saleem Isaaf Alazab, College of Law, Balqa Applied University, Al-Salt City, Jordan. E-mail: \\ dr.saleem-alazab@bau.edu.jo
}

Received: August 7, 2020

Accepted: August 31, 2020

Online Published: October 13, 2020

doi:10.5539/jpl.v13n4p181

URL: https://doi.org/10.5539/jpl.v13n4p181

\begin{abstract}
Article (326) of the Jordanian Penal Code does not differentiate between methods of willful murder. These methods include transmission of Covid-19, where such type of disease is considered contagious under Article (17) of Jordanian Public Health Law No. (47) of 2008. However, medical science has not certainly proven that the transmission of the virus to a victim is a viable method of infection that definitely causes death. This is since this result (death) might happen a long time after transmission of coronavirus to a victim.

It is difficult for the legislator to draft clear provisions that take into account the various circumstances of the willful murder and its sophisticated methods. Therefore, the trial judge is required to verify the existence of the causal relationship in each willful murder case based on its relevant circumstances.
\end{abstract}

Keywords: intentional homicide, causation, Jordanian penal law, Jordanian public health law, Corona virus

\section{Introduction}

Many studies, researches and experiments have been conducted to find out the nature of coronavirus that causes Covid-19 disease, how it is transmitted from a person to another and how it is prevented. However, these efforts were only attempts that have not yet discovered an effective treatment for the diseases caused by the virus. The number of persons infected with the virus has dramatically increased around the world since the first infection was announced in China in December 2019.

The emergence of the dangerous behaviors associated with Covid-19 disease caused by coronavirus has drawn attention of jurists to the importance of providing criminal protection for the right to life and the right to safety.

Recently, some criminal behaviors intended to transmit this virus to members of society have been discovered. This raised the question about the validity of applying the willful murder provisions of Jordanian Penal Code to the willful murder committed by transmitting the coronavirus to a healthy person. This is since imposing penalty for this crime, as it is a result crime, requires proving validity of this transmission mode to cause death as a result on the one hand. On the other hand, occurrence of murder requires proving that death certainly results from criminal behavior.

Driven by the desire to contribute to clarifying the solution to the above-mentioned problem that may arise when a person is accused of the willful murder by transmitting the coronavirus to a victim, I will examine the causal relationship in the willful murder using the analytical method in Jordanian legislation in order to arrive at specific perception to solve the said problem. Therefore, in dealing with the elements of the causal relationship, this study is divided into two parts: 1 . the criminal behavior in transmitting coronavirus to people who are not infected with it, and 2. the result of this crime, namely death:

\section{Criminal Behavior}

The criminal behavior in the willful murder exists when an offender performs any act that would end the life of a living person in the medical and legal sense agreed upon. This distinguishes the killing as a crime from the natural death that occurs without the intervention of another person, and from assaulting a corpse, or an animal that is not the subject of the willful murder.

Article 326 of the Penal Code, which provides that "Any person who willfully kills a person shall be punished by imprisonment for twenty years with hard labor", includes all methods of willful murder, and this method is not an 
element of commission of a crime. However, the ability of this method to cause killing by the coronavirus ${ }^{1}$ raises a legal problem related to its ability to make the result happen. Hence, it has been necessary to consult Article 17 of the Jordanian Public Health Law No. 47 of 2008, which labels coronavirus that causes Covid-19 disease, as an infectious disease ${ }^{2}$, where it provides that it is "the disease that is caused by microorganisms such as bacteria, viruses, fungi, parasites, and the like or by their toxins, and the causal infectious agent can be transmitted directly or indirectly to a person from the reservoir or source of the infection".

Paragraph (b) of Article (22) of the Jordanian Public Health Law No. (47) of 2008 penalizes the transmission of coronavirus, where it provides that: "Everyone who...exposes a person to an epidemic infection or intentionally transmits the infection to others or refrains from carrying out any action that has been requested to prevent the spread of infection, shall be considered guilty of a crime that is punishable under the provisions of this law".

This disease is different from other diseases associated with the infectious viruses since it rapidly spreads among people; therefore, the World Health Organization described it as a global pandemic ${ }^{3}$.The risk of this disease to the person infected with virus has increased due to the lack of effective treatment to date, especially when a patient's body is unable to resist it due to old age or health problems, or when there are a large number of people infected with the virus. This would overburden the health system in providing health services required for all patients, causing some deaths. ${ }^{4}$

The methods of transmitting the virus vary. Some methods are inherently capable of causing the result, such as intentionally sneezing in the face of a victim, spitting on him, or kissing him while leaving remnants of his saliva or mucus on a victim's body, or an infected defendant deliberately contacts with other people without taking precautions to prevent the transmission of the virus to them, for example, he refrains from isolating himself in the hospital or in his private home when he becomes aware of his infection. ${ }^{5}$

A defendant can also transmit the virus to other people by creating a method of killing whose effect ultimately appears under certain circumstances. This might happen if a defendant places his salvia or mucus on tools used by a victim, such as the doorknobs of his house or door handles of his car, or that he places, while he is aware of being infected with the virus, places masks - which he previously used - within the reach of people on public transportation to be reused by them, or that he blows air of his mouth contaminated with the virus on some food offered for sale in some stores.

While the earlier ways materially characterize the criminal behavior in transmission of virus to others, an offender might use moral ways that cause psychological pain to a victim with the intent to spread terror and fear after he untruthfully informs a victim of his infection using the physical weakness of a victim as a result of the chronic diseases that he suffers from. This kind of causes the death of a victim as a result of hearing the bad news. If this presumption is not excluded as a way used in the willful murder, the difficulty lies in proving the causal relationship between moral behavior and the result, on the one hand. On the other hand, though paragraph (b) of Article (22) of the Jordanian Public Health Law penalizes behaviors that help transmission of coronavirus, the presence of a causal relationship requires proving that Covid-19 disease that afflicted a victim -who did not have the virus that

\footnotetext{
${ }^{1}$ Coronaviruses are a large family of viruses which may cause illness in animals or humans. In humans, several coronaviruses are known to cause respiratory infections ranging from the common cold to more severe diseases such as Middle East Respiratory Syndrome (MERS) and Severe Acute Respiratory Syndrome (SARS). The most recently discovered coronavirus causes coronavirus disease COVID-19. See: https://www.who.int/ar/emergencies/diseases/novel-coronavirus-2019/advice-for-public/q-a-coronaviruses

2 COVID-19 is the infectious disease caused by the most recently discovered coronavirus. See: https://www.who.int/ar/emergencies/diseases/novel-coronavirus-2019/advice-for-public/q-a-coronaviruses

${ }^{3}$ This new virus and disease were unknown before the outbreak began in Wuhan, China, in December 2019. COVID-19 is now a pandemic affecting many countries globally. The most common symptoms of COVID-19 are fever, dry cough, and tiredness. Other symptoms that are less common and may affect some patients include aches and pains, nasal congestion, headache, conjunctivitis, sore throat, diarrhea, loss of taste or smell or a rash on skin or discoloration of fingers or toes. These symptoms are usually mild and begin gradually. Some people become infected but only have very mild symptoms. See: https:/www.who.int/ar/emergencies/diseases/novel-coronavirus-2019/advice-for-public/qa-coronaviruses

${ }^{4}$ Most people (about 80\%) recover from the disease without needing hospital treatment. Around 1 out of every 5 people who gets COVID-19 becomes seriously ill and develops difficulty breathing. Older people, and those with underlying medical problems like high blood pressure, heart and lung problems, diabetes, or cancer, are at higher risk of developing serious illness. See: https://www.who.int/ar/emergencies/diseases/novel-coronavirus-2019/advice-for-public/q-a-coronaviruses

${ }^{5}$ People can catch COVID-19 from others who have the virus through small droplets from the nose or mouth, which are expelled when a person with COVID-19 coughs, sneezes, or speaks. These droplets are relatively heavy, do not travel far and quickly sink to the ground. People can catch COVID-19 if they breathe in these droplets from a person infected with the virus. These droplets can land on objects and surfaces around the person such as tables, doorknobs and handrails. People can become infected by touching these objects or surfaces, then touching their eyes, nose or mouth. See, https://www.who.int/ar/emergencies/diseases/novel-coronavirus-2019/advice-for-public/q-a-coronaviruses
} 
caused his death - has certainly resulted from the virus transmitted to him by an offender. Also, the medical science has not confirmed yet that the death-imminent or distant - definitely results from the virus infection. ${ }^{6}$

Faced with these difficulties, I argue that the trial judge to whom the case of the accusation of the willful murder is brought has a discretionary authority to verify a causal relationship between the death of the victim as a result, and the transmission of the virus as a method to prove a criminal behavior in each case of willful murder brought according to its own circumstances, including killing by moral methods. It should be mentioned here that the judge's characterization of the crime as the attempted willful murder is less difficult than proving that an offender's behavior is intended to kill a victim, whether he is able transmit this virus to a victim or he is unable to do so due to circumstances beyond his control.

\section{Result}

Result crime means a crime requires a prohibited result as an essential element, i.e. a required result must happen in order for a crime to have occurred. Hence, the presence of a causal relationship in the willful murder requires a result, i.e. the death of the victim, regardless of the death's time, as the time interval between the behavior and the result has no effect on the establishment of the causal relationship ${ }^{7}$. Such relationship is present even if the result happens after years due to virus incubation period in a victim's body that is infected with the virus. The victim's body resistance to the coronavirus plays a significant role in prolonging or shortening the time in which the result happens; according to medical research ${ }^{8}$.

After transmitting virus to the victim's body, any attempt by an offender to save a victim's life will not exempt him from penalty, as medical science has not yet found an effective treatment to remove the effects of the virus from the victim's body ${ }^{9}$. However, this attempt by an offender might be deemed a ground for mitigation of penalty, on the one hand. On the other hand, this relationship is also present when the death occurs without the intervention of other factors that facilitate its occurrence. The question arises here is what if there are other factors associated with an offender's behavior that help a result to happen?

In order to answer this question, the Penal Code must be consulted to find out how the Jordanian legislator addresses this question. It is found that he does not specify a period of time if there is a gap between the result and the behavior. Hence, failure to specify of the time period for the result to happen is acceptable as long as the causal relationship between the behavior and the result exists. In other words, the gap between the result and the behavior does not affect existence of such relationship. We argue that it is very difficult to determine a time period in terms of drafting clear legislative texts that take into account the circumstances of the various murders and evolving criminal behaviors, where determination of criterion of causality, which the legislator might adopt, might become invalid after a short time..$^{10}$

Article 354 of the Jordanian Penal Code provides that "If the willfully committed death or injury were the result of pervious causes not known for the perpetrator and were independent from his/her acts, he/she shall be punished

\footnotetext{
${ }^{6}$ COVID-19 is mainly spread through respiratory droplets expelled by someone who is coughing or has other symptoms such as fever or tiredness. Many people with COVID-19 experience only mild symptoms. This is particularly true in the early stages of the disease. It is possible to catch COVID-19 from someone who has just a mild cough and does not feel ill. Some reports have indicated that people with no symptoms can transmit the virus. It is not yet known how often it happens. See: https://www.who.int/ar/emergencies/diseases/novel-coronavirus2019/advice-for-public/q-a-coronaviruses

${ }^{7}$ In this regard, the Jordanian court of cassation ruled that" the immediate death of a victim is not necessary to prove the intent to kill. Existence of evidence is sufficient to prove such intent, such as the instruments used by an offender, the point and seriousness of injury". A judgment by the Jordanian court of cassation $\quad$ No. 53/1968, issued $\quad$ on1.1.1986.see: https://qarark.com/courts?page=1\&content=\%D9\%86\%D9\%8A\%D8\%A9\%20\%D8\%A7\%D9\%84\%D9\%82\%D8\%AA $\%$ D9\%84\%20\%D8\% A3\%D9\%86\%20\%D9\%8A\%D9\%85\%D9\%88\%D8\%AA\%20\%D8\%A7\%D9\%84\%D9\%85\%D8\%AC\%D9\%86\%D9\%8A\%20\%D8\%B9\%D 9\%84\%D9\%8A\%D9\%87\%20\%D9\%81\%D9\%8A\%20\%D8\%A7\%D9\%84\%D8\%AD\%D8\%A7\%D9\%84\&content_type=c1\&contentType=c $1 \&$ dcourt $=0 \&$ dtextSearch $=0 \&$ legType $=0 \&$ agrType $=0$ \&etype $=0 \&$ currentPage $=1 \&$ id $=$ zdzbvhTcwNXLzFTM10CNzEXNtkjNwdTL2AXOx NnMuBjM0czc

${ }^{8}$ See the Article titled: He was diagnosed with the virus 3 times. How long does "Corona" remain in the body? https://www.alhurra.com/health/2020/05/06/\%D8\%AA\%D9\%85-\%D8\%AA\%D8\%B4\%D8\%AE\%D9\%8A\%D8\%B5-\%D8\%A5\%D8\%B5\% D8\%A7\%D8\%A8\%D8\%AA\%D9\%87-\%D8\%A8\%D8\%A7\%D9\%84\%D9\%81\%D9\%8A\%D8\%B1\%D9\%88\%D8\%B33-\%D9\%85\%D8\%B1\%D8\%A7\%D8\%AA-\%D9\%83\%D9\%85-\%D8\%A7\%D9\%84\%D9\%85\%D8\%AF\%D8\%A9-\%D9\%8A\%D8\%A8\%D9 \%82\%D9\%89-\%D9\%81\%D9\%8A\%D9\%87\%D8\%A7-\%D9\%83\%D9\%88\%D8\%B1\%D9\%88\%D9\%86\%D8\%A7-\%D9\%81\%D9\%8A-\%D $8 \% \mathrm{~A} 7 \% \mathrm{D} 9 \% 84 \% \mathrm{D} 8 \% \mathrm{AC} \% \mathrm{D} 8 \% \mathrm{~B} 3 \% \mathrm{D} 9 \% 85 \% \mathrm{D} 8 \% 9 \mathrm{~F}$

${ }^{9}$ There are no medicines that have been shown to prevent or cure the disease. However, there are several ongoing clinical trials of both western and traditional medicines. WHO is coordinating efforts to develop vaccines and medicines to prevent and treat COVID-19. See:https://www.who.int/ar/emergencies/diseases/novel-coronavirus-2019/advice-for-public/q-a-coronaviruses

${ }^{10}$ Dr. Mohammad Udeh Al-Jbour, Crimes against Persons, $2^{\text {nd }}$ edition, Wael Publishing House, Amman, 2012, p.54.
} 
as follows:

1) Imprisonment with hard labor for a period not less than ten years if his / her action requires the death penalty or life imprisonment with hard labor.

2) The reduction of any penalty by half if his / her action requires a penalty other than the death penalty or life imprisonment with hard labor".

Under the said Article ${ }^{11}$, a defendant is held responsible even if other independent factors have led to occurrence of the result. However, such factors are deemed to be mitigating factors for the crime of willful murder, provided that a defendant is unaware of such factors. It does not matter whether such factors exist before, during or after a defendant's behavior, where lack of knowledge about the other factors, associated with and independent of a defendant's act, are deemed to be a cause to mitigate the penalty. However, if a defendant is aware of the other factors, or that such factors result from his act, penalty is not mitigated. Rather, a defendant remains responsible for the death though other factors are associated with his act and contribute to causing the death. We argue that a defendant is still responsible for the willful murder in case of inability to treat a victim in light of the inability of the health system to provide health care to him due to the large number of people infected with the virus, or due to epidemiological situation, or the lack of treatment for diseases caused by the virus.

In accordance with Article 64 of the Penal Code which provides that "a crime is considered to be deliberate even if the criminal consequence of the act exceeded the intent of the perpetrator, provided that he / she expected such consequence and accepted the risk of its occurrence", if the causal relationship exists, a defendant is held

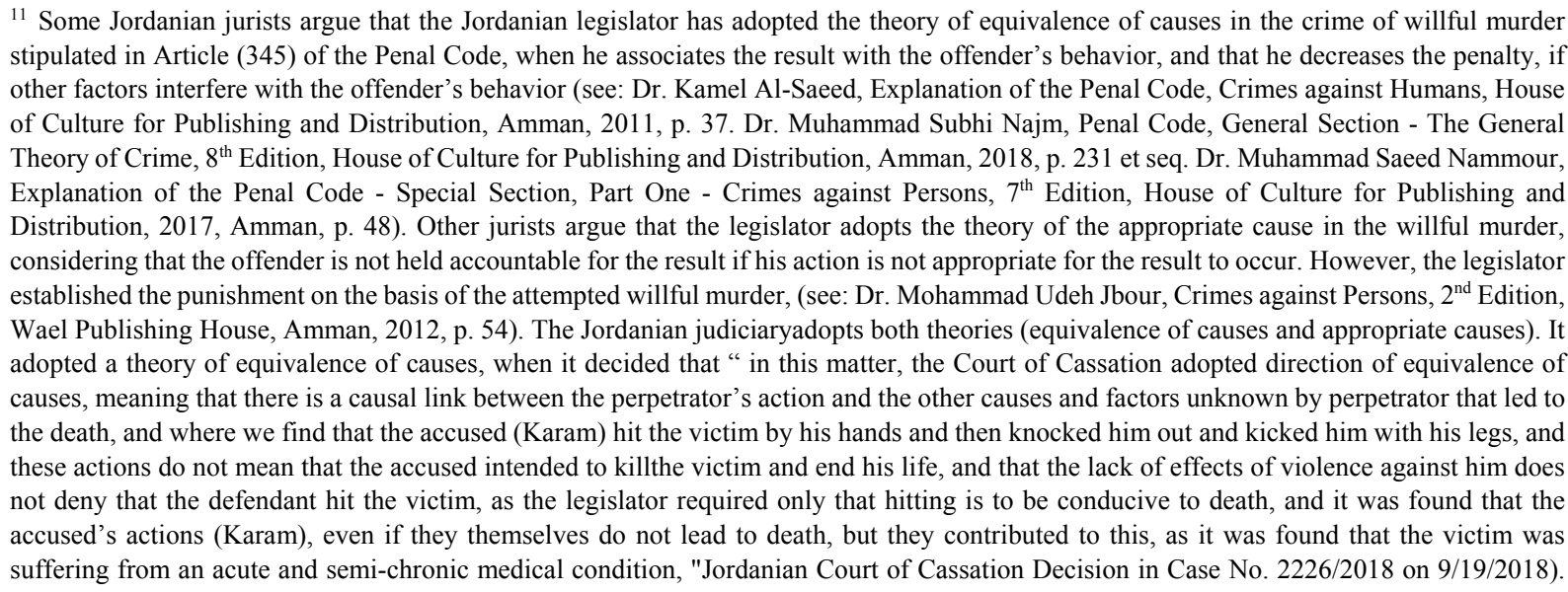
See:

https://qarark.com/courts?page=1\&content=\%D8\%AA\%D8\%B9\%D8\%A7\%D8\%AF\%D9\%84\%20\%D8\%A7\%D9\%84\%D8\%A7\%D8\%B3 \%D8\%A8\%D8\%A7\%D8\%A8\%20\%D8\%A7\%D9\%84\%D8\%B3\%D8\%A8\%D8\%A8\%D9\%8A\%D8\%A9\%20\%D8\%A7\%D9\%84\%D9\%85 $\% \mathrm{D} 9 \% 84 \% \mathrm{D} 8 \% \mathrm{~A} 7 \% \mathrm{D} 8 \% \mathrm{~A} 6 \% \mathrm{D} 9 \% 85 \% \mathrm{D} 8 \% \mathrm{~A} 9 \&$ content type $=\mathrm{c} 2 \&$ contentType $=\mathrm{c} 2 \&$ dcourt $=0 \&$ dtextSearch $=0 \&$ legType $=0 \&$ agrType $=0$ \&etype $=0$ \&currentPage $=1 \& \mathrm{id}=$ zcjN34WNuZTL0Ezb10CN1ATMtkzbygTL0AHN4kTMxNDNxAzN.

The Jordanian court of cassation ruled that "In this matter, the Court of Cassation in this matter has taken the direction of equivalence of causes, meaning that there is a causal link between the perpetrator's act and the other causes and factors unknown by the offender that led to the death, and where we find that the accused intended to harm the victim (Ibrahim) since he did not use an inherently lethal tool. Rather, he used his leg to hit the victim on the chest, where his head crashed into the wall accordingly, which led to hemorrhage from the right side of the brain that led to death. Another cause contributed to the happening of the result, namely the medical procedures that had to be taken on the victim by the physician examined him for the first time, and he did not take any action, and that the delay in taking medical procedures contributed to and helped in the occurrence of the result, which is death. Jordanian Court of Cassation Decision No. 2230/2018 dated 9/13/2018, see: https://qarark.com/courts?page=1\&content=\%D8\%AA\%D8\%B9\%D8\%A7\%D8\%AF\%D9\%84\%20\%D8\%A7\%D9\%84\%D8\%A7\%D8\%B3 \%D8\%A8\%D8\%A7\%D8\%A8\%20\%D8\%A7\%D9\%84\%D8\%B3\%D8\%A8\%D8\%A8\%D9\%8A\%D8\%A9\%20\%D8\%A7\%D9\%84\%D9\%85 $\% \mathrm{D} 9 \% 84 \% \mathrm{D} 8 \% \mathrm{~A} 7 \% \mathrm{D} 8 \% \mathrm{~A} 6 \% \mathrm{D} 9 \% 85 \% \mathrm{D} 8 \% \mathrm{~A} 9 \&$ content type $=\mathrm{c} 2 \&$ content Type $=\mathrm{c} 2 \&$ dcourt $=0 \&$ dtextSearch $=0 \&$ legType $=0 \&$ agrType $=0$ \&etype $=0$ \&currentPage $=1 \&$ id=1gjN0Yjc1gTLyVTN30CNxdTMtgTM4cTL1gTN2QjN2MHMxETc

In contrast, he Jordanian judiciary adopted the theory of appropriate causes $n$ when it ruled that "the accused did not intend to kill him, but rather the death of the victim was due to car accident and not and not due the gunshot fired by the accused, where other factors intertwined with the act of the accused and independent of him, and there was a link The causation is between them and the independent factor which is exposure to intrusion is expected in such circumstances and it is not conceivable that the result will occur without the defendant's act and therefore the accused is asked about the result according to the appropriate causal theory and is punished with the same punishment prescribed for the crime that occurred and is causing death resulting from a trauma accident. Case No. 333/2020 of 4/8/2020, see: https://qarark.com/courts?page=1\&content=\%D8\%AA\%D8\%B9\%D8\%A7\%D8\%AF\%D9\%84\%20\%D8\%A7\%D9\%84\%D8\%A7\%D8\%B3 \%D8\%A8\%D8\%A7\%D8\%A8\%20\%D8\%A7\%D9\%84\%D8\%B3\%D8\%A8\%D8\%A8\%D9\%8A\%D8\%A9\%20\%D8\%A7\%D9\%84\%D9\%85 $\% \mathrm{D} 9 \% 84 \% \mathrm{D} 8 \% \mathrm{~A} 7 \% \mathrm{D} 8 \% \mathrm{~A} 6 \% \mathrm{D} 9 \% 85 \% \mathrm{D} 8 \% \mathrm{~A} 9 \&$ content type $=\mathrm{c} 2 \&$ contentType $=\mathrm{c} 2 \& \mathrm{dcourt}=0 \&$ dtextSearch $=0 \&$ legType $=0 \&$ agrType $=0$ \&etype $=0$ \&currentPage $=1 \&$ id=4gTN2AHMzdTL5EXcu1CN3AHNtgjbvJTL4IHOxFDczFXMylzM 
responsible for the direct result intended by a defendant, and for the possible or expected result of the behavior of the victim infected with the virus who does not intend to create it directly.

Causality is based on provisions. Such provisions do not include the matters expected by a person infected with the virus or the thoughts or intents that come to his mind. Rather, what only matters is existence of causality between behavior and the result. It is not accepted by such person to invoke that the death of the victim due to transmission of coronavirus to him did not result from the matters he expected or things came to his mind, disclaiming the responsibility for the willful murder. This is since his criminal behavior had its potential and expected consequences if he was aware that he was infected with the virus. Nevertheless, he had contact with the victim knowing that he might catch the virus, and he did not reject the result, possible death, and he did nothing to prevent it, rather he did not care whether the result could happen or not. Therefore, his behavior falls within the scope of the constructive malice, to which the penalty for direct intent applies, according to Article (64) of the Penal Code.

In the event that the result required for the existence of the causal relationship in the crime of willful murder does not happen, then this crime is considered an offense of attempt. The offense of attempt means that some impediment, other an offender's will, prevents him from completing his behavior, where if such impediment was absent, an offender would complete such behavior. This crime is called a suspended crime. For example, an offender attempts to spit on tools used by a victim, but the victim prevents him from doing so.

On the other hand, the attempted willful murder exists if an offender has completed his criminal behavior, but the result of this behavior has not happened for reasons beyond his will. This crime is called a failed crime, since the result does not happen. This may occur if a victim takes an action that prevents the result, where he, for example, wipes buttons of an elevator in an apartment building with a disinfectant that removes effects of the virus placed by an offender through his saliva or mucus contaminated with the virus. Also, this might be due to failure of the offender infected with the virus to transmit the virus to the victim, where the result is does not happen for many reasons including, for example, a victim's immune system is able to create antibodies to the virus, and they kill the virus. Also, the medical science has developed an effective treatment to eliminate the virus and its effects on the victim's body, and the victim has recovered from the virus after taking this treatment.

Additionally, absence of result might be due to inability of the method used by an offender.

This may occur if the offender mistakenly believes that he is infected with the virus, as he has a fever-for example - as a result of a bacterial and not a viral infection. Also, absence of result might be due to the lack of loci delicti. For example, an offender places his saliva or mucus contaminated with the virus on tools belonging to the victim, but he does not catch the virus despite using contaminated tools, either because an offender's saliva or mucus does not originally contain the virus or because the body of the victim has antibodies against the virus ${ }^{12}$, or he had previously been infected with the virus, and he recovered from its effects, thus becoming unable to receive it again. ${ }^{13}$

\section{Conclusion}

Examination of "Causality in the Crime of Willful Murder by Transmission of Coronavirus" has constituted a barrier to applying the general provisions concerning the willful murder under Article (326) of the Jordanian Penal Code to the willful murder committed by transmitting coronavirus to others. This barrier is noticed in two aspects. The first is the problem of the inability of the method to cause murder when an offender performs a criminal behavior, and the second is a problem of proving with certainty that death is the result of the behavior of an offender. Undoubtedly, discussing the problems raised by this study is not less important than providing definitive solutions.

\footnotetext{
${ }^{12}$ Antibodies are defined as proteins produced by the immune system in response to a viral or bacterial attack or any other cause of the disease. Antibodies destroy pathogens that invade the body by attaching to them to become harmless, or by distinguishing these cells so that they can be easily eliminated. The antibodies remain in the bloodstream after infection, in anticipation of the virus return. If the virus returns, the antibodies are ready to attack it, and then the virus stimulates a rapid immune response that we might think is the same infection. Therefore, the patient in the recovery phase acquires immunity to the virus, which prevents the recurrence of infection. William Park by, Coronavirus: What are the chances of being infected twice? an article published on the B.B.C website 4-27-2020 on the Internet: https://www.bbc.com/arabic/vert-fut-52413699.

13 Dr. Mahmoud Omar Mahmoud, Criminal Responsibility for Transmission of COVID-19, p.11, an article published online, http://www.mediafire.com/file/k1 ojliim3qsp2y4/\%25D8\%25A7\%25D9\%2584\%25D9\%2585\%25D8\%25B3\%25D8\%25A6\%25D9\%2588\% 25D9\%2584\%25D9\%258A\%25D8\%25A9_\%25D8\%25A7\%25D9\%2584\%25D8\%25AC\%25D9\%2586\%25D8\%25A7\%25D8\%25A6\%25 D9\%258A\%25D8\%25A9_\%25D8\%25B9\%25D9\%2586 \%25D9\%2586\%25D9\%2582\%25D9\%2584_\%25D8\%25B9\%25D8\%25AF\%25D 9\%2588\%25D9\%2589_\%25D9\%2581\%25D9\%258A\%25D8\%25B1\%25D9\%2588\%25D8\%25B3_\%25D9\%2583\%25D9\%2588\%25D8\%2 5B1\%25D9\%2588\%25D9\%2586\%25D8\%25A7_\%25D8\%25A7\%25D9\%2584\%25D9\%2585\%25D8\%25B3\%25D8\%25AA\%25D8\%25AC $\% 25 \mathrm{D} 8 \% 25 \mathrm{AF} . \mathrm{pdf} /$ file
} 
In order to contribute to developing a perception to solve this problem, this study is divided into two parts. The first part deals with the criminal behavior. It is concluded that Article (326) of the Penal Code includes all methods of murder. Hence, it has become clear that the coronavirus is an infectious disease as described in Article 17 of the Jordanian Public Health Law No. 47 of 2008, and that the transmission of this virus to the victim is a punishable behavior under paragraph (b) of Article (22) of the Jordanian Public Health Law No. 47 of 2008. Moreover, it must be proven that the virus that causes Covid-19 disease and then death is certainly transmitted by the offender himself and not by another person. If the offender's behavior fails to actually transmit the infection to the victim, then he will only be held responsible for attempted willful murder. However, if the victim is actually infected with the virus due to an offender's behavior, then, in order for an offender to be held responsible for an attempted willful murder, the result must happen. It has not been proven by medical science until now that the transmission of the virus is a conclusive result of infection with the virus and ultimately the death, sooner or later. In principle, this constitutes a problem in providing a causal relationship in the case where there is a gap between the result and the behavior, where an offender may die without punishment. We argue that it is very difficult to determine a time period in terms of drafting clear legislative texts that take into account the circumstances of the various murders and evolving criminal behaviors, where determination of criterion of causality, which the legislator might adopt, might become invalid after a short time.

Hence, it would be advisable to leave this matter to the trial judge who tries the case of willful murder, where he has discretion to prove the existence of a causal relationship between the deathof a victim as a result, and the transmission of the virus as a cause.

The trial judge has a significant role in verifying the existence of the causal relationship in each willful murder case based on its own circumstances.

\section{References}

Al-Saeed, K. (2011). Explanation of the Penal Code, Crimes against Humans. House of Culture for Publishing and Distribution, Amman.

Nammour, M. S. (2017). Explanation of the Penal Code - Special Section, Part One - Crimes against Persons (7th ed.). House of Culture for Publishing and Distribution, Amman.

Najm, M. S. (2018). Penal Code, General Section - The General Theory of Crime (8th ed.). House of Culture for Publishing and Distribution, Amman.

Al-Jbour, M. U. (2012). Crimes against Persons (2nd ed.). Wael Publishing House, Amman.

\section{Copyrights}

Copyright for this article is retained by the author(s), with first publication rights granted to the journal.

This is an open-access article distributed under the terms and conditions of the Creative Commons Attribution license (http://creativecommons.org/licenses/by/4.0/). 